\title{
Imagen \\ El único fósil de dinosaurio de Centroamérica fue descubierto en Honduras en 1971
}

Central America's only dinosaur fossil was discovered in Honduras in 1971

Leonel E. Zúniga ${ }^{1}$

Departamento de Biología, Universidad Nacional Autónoma de Honduras, Tegucigalpa, Honduras

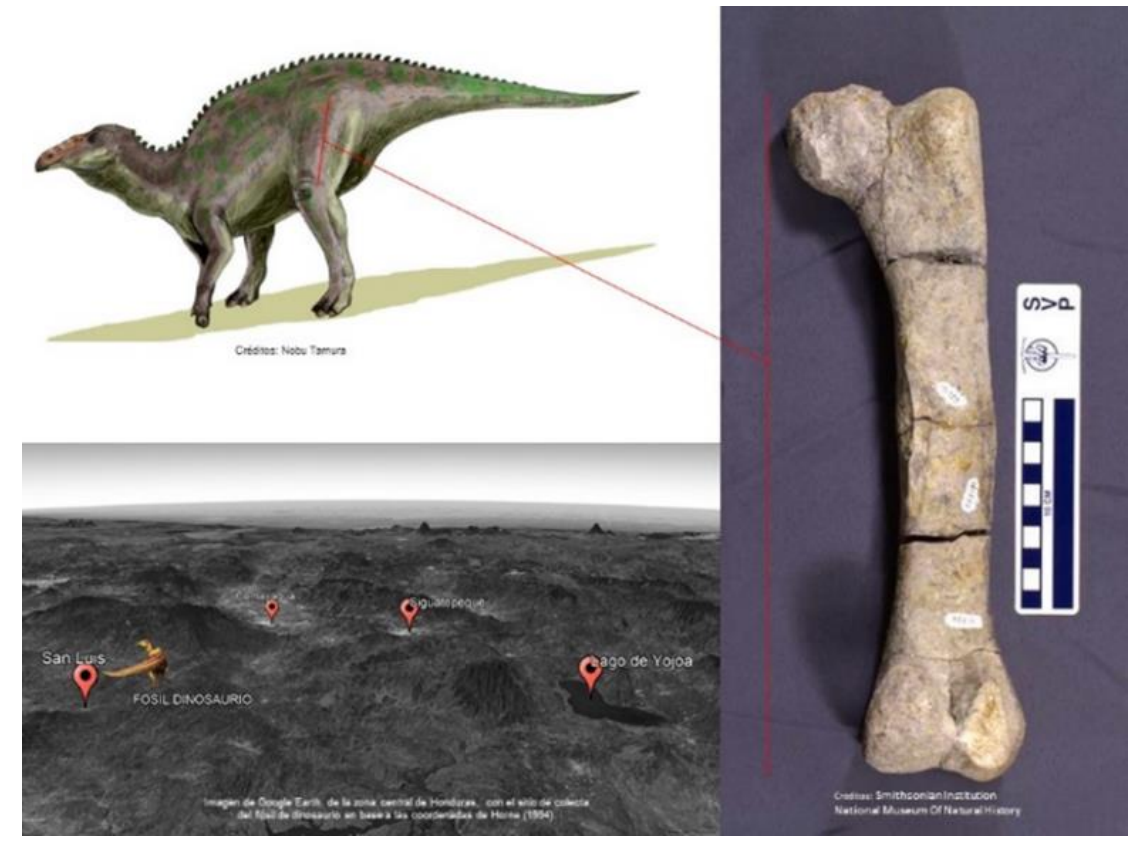

En 1971, Gregory Horne, un geólogo norteamericano de Wesleyan University, descubrió en Honduras el único fósil de dinosaurio encontrado en Centroamérica durante una gira de investigación geológica cerca de San Luis, Comayagua (Zúniga, 2017). El fósil, un fémur de un dinosaurio ornitópodo, hadrosauroideo, se encuentra actualmente en el Museo de Historia Natural en Washington D.C. (Instituto Smithsonian) bajo el código USNM PAL 181339 (Reproducido con permiso). Su identificación fue confirmada por paleontólogos reconocidos como Jack McIntosh y John R. Horner (Horne, 1994). El fósil sugiere un potencial intercambio biológico de dinosaurios entre América del Norte y América del Sur (Rage, 1981), planteando un desafío a las teorías sobre la formación geológica de Centroamérica.

\section{Referencias Bibliográficas}

Horne, G. S. (1994). A mid-Cretaceous ornithopod from central Honduras. Journal of Vertebrate Paleontology, 14(1), p. 147-150.

Rage, J. C. (1981). Les continents péri-atlantiques au Crétacé supérieur: migrations des faunes continentales et problèmes paléogéographiques. Cretaceous Research, 2(1), p. 65-84.

Zúñiga, L. (2017). Evidencia fósil de dinosaurios: un aporte a la historia de la paleontología en Centroamérica. Revista Ciencia y Tecnología, (20), p. 2949.

\footnotetext{
${ }^{1}$ Autor corresponsal: lzunigamg@gmail.com. Departamento de Biología, Piso 3, Edificio J1, Ciudad Universitaria, Tegucigalpa, Honduras Historia del Artículo: Recibido: 9 diciembre 2019; Revisado: 12 diciembre 2019; Aceptado: 13 diciembre 2019; Disponible en línea: 30 diciembre 2019 Disponible en https://doi.org/10.5377/innovare.v8i2.8960

(C) 2019 Autores y UNITEC. Este es un artículo de acceso abierto según licencia http://creativecommons.org/licenses/by-nc-nd/4.0
} 